\title{
Fully Integrated Oncology and Palliative Care Services at a Local Hospital in Mid-Norway: Development and Operation of an Innovative Care Delivery Model
}

\author{
Anne-Tove Brenne (D) - Anne Kari Knudsen - Sunil Xavier Raj · \\ Laila Skjelvan · Jo-Åsmund Lund · Morten Thronæs • Erik Torbjørn Løhre • \\ Liv Ågot Hågensen · Cinzia Brunelli · Stein Kaasa
}

Received: January 27, 2020 / Published online: April 9, 2020

(C) The Author(s) 2020

\begin{abstract}
Introduction: Early access to cancer palliative care is recommended. Descriptions of structures and processes of outpatient palliative care clinics operated within smaller hospitals are scarce. This paper presents the development and operation of a fully integrated cancer and palliative care outpatient clinic at a local hospital in a rural region of Mid-Norway offering palliative care concurrent with cancer treatment. A standardized care pathway was applied.
\end{abstract}

Enhanced Digital Features To view digital features for this article go to https://doi.org/10.6084/m9.figshare. 11991486.

A.-T. Brenne $(\bowtie) \cdot$ S. X. Raj · L. Skjelvan ·

J.-Å. Lund · M. Thronæs · E. T. Løhre

European Palliative Care Research Centre (PRC),

Department of Clinical and Molecular Medicine,

Faculty of Medicine and Health Sciences, Norwegian

University of Science and Technology, Trondheim,

Norway

e-mail: anne.tove.brenne@ntnu.no

A.-T. Brenne - S. X. Raj · L. Skjelvan · M. Thronæs ·

E. T. Løhre

Cancer Clinic, St. Olavs Hospital, Trondheim

University Hospital, Trondheim, Norway

A. K. Knudsen · S. Kaasa

European Palliative Care Research Centre (PRC),

Oslo University Hospital and University of Oslo,

Oslo, Norway
Methods: Palliative care is in Norway part of the public healthcare system. Official recommendations recent years point out action points to improve delivery of palliative care. An integrated cancer and palliative care outpatient clinic at a local hospital and an innovative care delivery model was developed and operated in this setting. Patients were recruited for a descriptive study of the patient population. Clinical data were collected by clinical staff and 13 symptom intensities were reported by the patients.

Results: Cancer and palliative care were provided by one team of healthcare professionals trained in both fields. There was a close collaboration with the other departments at the hospital, with its affiliated tertiary hospital, and

\section{A. K. Knudsen · S. Kaasa}

Department of Oncology, Oslo University Hospital, Oslo, Norway

\section{J.-Å. Lund}

Department of Oncology, Ålesund Hospital, Møre og Romsdal Hospital Trust, Ålesund, Norway

L. Å. Hågensen

Coordination Unit Orkdal Region, Orkdal, Norway

C. Brunelli

Palliative Care, Pain Therapy and Rehabilitation Unit, Fondazione IRCCS Instituto Nazionale dei Tumori, Milan, Italy

S. Kaasa

Institute of Clinical Medicine, Faculty of Medicine, University of Oslo, Oslo, Norway 
with community health and care services to provide timely referral, enhanced continuity, and improved coordination of care. Eightyeight patients were included. Mean age was 65.6 years, the most common cancer diagnoses were digestive organs (22.7\%), male genital organs $(20.5 \%)$ or breast $(25.0 \%), 75.0 \%$ had metastatic or locally advanced cancer, $59.1 \%$ were treated with non-curative intention and 93.1\% had Karnofsky Performance Status $\geq 80 \%$. Median scores of individual symptoms ranged from 0 to 3 (numerical rating scale, $0-10)$ and $61.0 \%$ reported at least one clinically significant symptom rating $(\geq 4)$.

Conclusion: This delivery model of integrated outpatient cancer and palliative care is particularly relevant in rural regions allowing cancer patients access to palliative care earlier in the disease trajectory and closer to home

\section{PLAIN LANGUAGE SUMMARY}

Palliative care is an important part of cancer care which aims at improving cancer patients' symptom burden and quality of life and support their carers. Palliative care has traditionally been separated from cancer care. During the last decade, one has become aware of the benefits of introducing palliative care early and concurrent with cancer treatment. Most cancer patients are nowadays treated as outpatients. Availability of palliative care as a routine part of outpatient cancer clinics is therefore important. Most of the described models of early palliative care in cancer care are within large tertiary hospitals. Here it is described how early palliative care was delivered to cancer patients in an outpatient clinic in a smaller hospital in a rural region of Mid-Norway. In this integrated cancer and palliative care outpatient clinic, cancer and palliative care were provided by one team of healthcare professionals trained in both fields. The integrated outpatient clinic collaborated closely with the other hospital departments and with community health and care services. This was needed to be able to offer palliative care to all cancer patients in need of it, and closer to their home. Many of the patients attending the integrated outpatient clinic could not be cured for their cancer. They did not have many symptoms of their cancer, and they had a high functional status. This demonstrated that the integrated outpatient clinic in this local hospital was a relevant place to offer palliative care early and concurrent with cancer treatment before symptoms became severe.

Keywords: Cancer palliative care; Care delivery model; Early integration; Outpatient clinic; Rural region

\section{Key Summary Points}

\section{Why carry out this study?}

Access to palliative care early in the cancer disease trajectory is recommended.

Description of delivery models of integrated cancer and palliative care within smaller hospitals and integrated with community care in rural districts is lacking.

This publication presents the development and operation of a fully integrated decentralized cancer- and palliative care program at an outpatient clinic at a local hospital in a rural region of Mid-Norway.

\section{What was learned from this study?}

Cancer and palliative care were at the outpatient clinic provided by one team of healthcare professionals trained in both fields collaborating closely with the other departments at the hospital, the affiliated tertiary hospital and health and care services in the surrounding communities.

A high proportion of cancer patients attending the integrated outpatient clinic was treated with non-curative intention and had low symptom burden, making it possible to offer palliative care services at an early stage of the cancer disease before symptoms became severe. 


\section{INTRODUCTION}

Palliative care aims at improving cancer patients' symptom burden and quality of life, and at supporting their carers [1]. It has been recognized as one of the important approaches in the treatment of cancer together with surgery, radiotherapy, and chemotherapy $[2,3]$. In the traditional model of cancer care the provision of curative and palliative care were often separated [4], delaying access to palliative care, and limiting its effectiveness [5]. Access to palliative care early in the cancer disease trajectory is associated with improved quality of life, improved satisfaction with care, reduced symptom burden, increased survival, fewer admissions to hospital during end of life, more time spent at home, and more patients dying at home [6-10]. The applied delivery models for early access to palliative care for cancer patients varied considerable between the published studies. Some contained regular consultations every month with a palliative care nurse, either as visits at an outpatient clinic $[7,8,10]$, or as telephone consultations [6]. Palliative care physicians were seen regularly $[7,8]$, or on demand $[6,10]$. The content of the consultations varied between the models, but all focused on symptom control and psychological distress, and used structured or semi-structured approaches $[6-8,10]$.

Since most cancer patients are nowadays treated as outpatients $[7,11,12]$, availability of palliative care as a routine part of outpatient cancer clinics is important [5]. Most of the reported models of palliative care delivery in outpatient clinics were structured and operated within tertiary hospitals as an add-on service to standard cancer care [13-16]. Descriptions of structures and processes of palliative care outpatient clinics operated within smaller hospitals were rarely found in the literature $[13,17,18]$. Community-based palliative care services have been promoted as the way to meet the increasing demand for palliative care [2, 19]. Results from clinical trials from e.g. Norway [20], Canada [8], and Japan [21] showed that the establishment of a specialized palliative care team working in close collaboration with community care can improve treatment and care for cancer patients [22]. Therefore, development, descriptions, and evaluations of complex organization models facilitating early access to palliative care for cancer patients in outpatient clinics operated within local hospitals integrated with community care are needed $[2,23]$.

A palliative care delivery model is a complex structure that needs well-defined, sustainable plans for development and implementation. Standardized care pathways (SCP) have been proposed as a method to plan and implement complex clinical care like the integration of palliative care into cancer care and can be used to structure the approach [2]. A care pathway in healthcare has by the European Pathway Association been defined as a method for management of a well-defined group of patients during a welldefined period of time [24]. The overall intention is to improve coordination and quality of treatment and care, reduce variation, and optimize use of resources [25]. In palliative cancer care, SCP can be used to define actions that have to be taken at specific transition points (Fig. 1) [2, 26].

An innovative fully integrated model formatting decentralized cancer care was developed and implemented at a local hospital in a rural region of Mid-Norway. The model consisted of a cancer and a palliative care program at an outpatient clinic (hereafter: Integrated Clinic). Our hypothesis was that this is a sustainable model for giving cancer patients early access to high quality palliative care closer to their home in a rural district. The objective of this publication was to present the process of the development of the Integrated Clinic and its operation structure. A pilot study describing the patient population attending the Integrated Clinic was provided.

\section{METHODS}

\section{Setting Within Which the Integrated Clinic Was Developed}

\section{Healthcare in Norway}

Norway has 5.3 million inhabitants in a country of the size of California. The Norwegian 


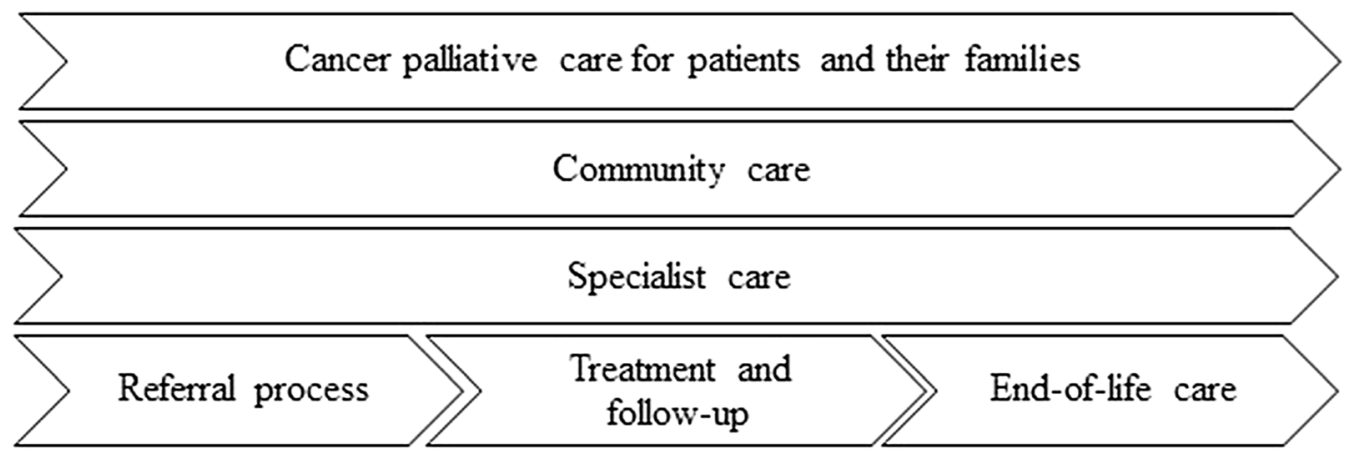

Fig. 1 Example of SCP aiming at improving coordination and quality of treatment and care across healthcare levels

healthcare system is divided into hospital/specialist care and community care, both financed by the government through different mechanisms [27]. Hospital care is the responsibility of the central government and is managed by four Regional Health Authorities. It is financed through block grants and activity-based funding. Community care includes rehabilitation, physiotherapy, home care nursing and nursing homes, primary emergency services, public health, and preventive medicine. Community care is managed and funded by the local municipal authorities through municipal taxes, block grants from the central government, and earmarked grants for specific purposes. Every Norwegian resident is assigned a general practitioner (GP), and each GP is fully responsible for a defined group of on average 1100 patients [28]. In general, inpatient hospital care and home care are free of charge. GP visits, outpatient hospital care, physiotherapy, rehabilitation, radiology and laboratory tests, and longterm institutional care require various degree of co-payment. When users have paid a certain amount throughout a calendar year (2369 NOK or 270 USD in 2019), user fees for public healthcare are waived for the rest of the year.

\section{Cancer Palliative Care in Norway}

In Norway, palliative care is part of the public healthcare system. Palliative care has, especially in oncology, been gradually developed at all levels of care since the early 1980s, in line with a series of official reports and national plans $[27,29]$. A recent Official Norwegian Report on palliative care for all life-threatening illnesses points out a series of action points to improve the delivery of palliative care in Norway [30].

There are four regional university hospitals with regional advisory units in palliative care in Norway. The Norwegian palliative care model is described in Fig. 2. At community level, palliative care for patients staying at home is provided by GPs and community care nurses. Palliative care beds are available in designated inpatient units in community nursing homes [31]. At hospital care level, palliative care teams provide consultations in hospital departments and ambulatory visits in surrounding municipalities. Palliative care units are available in larger hospitals [31]. Tertiary palliative care is provided in university hospitals. Norwegian national guidelines for cancer palliative care defines the competency framework and the organization of palliative care [32].

In most parts of Norway, there are networks of resource nurses in cancer and palliative care who act as a bridge between hospital and community care [31]. A resource nurse is a nurse with additional competence in cancer and palliative care equivalent to at least level $\mathrm{B}$ as described in Norwegian national guidelines for cancer palliative care [32]. In the municipalities, they have earmarked positions to coordinate and improve cancer care. After discharge from hospital, they are 'contact nurses' for the cancer patients, both in curative and palliative setting, and contribute to coordination and follow-up in close collaboration with the GPs and the hospitals.

The ambition of the National Cancer Strategy 2013-2017, being continued for 2018-2022, 


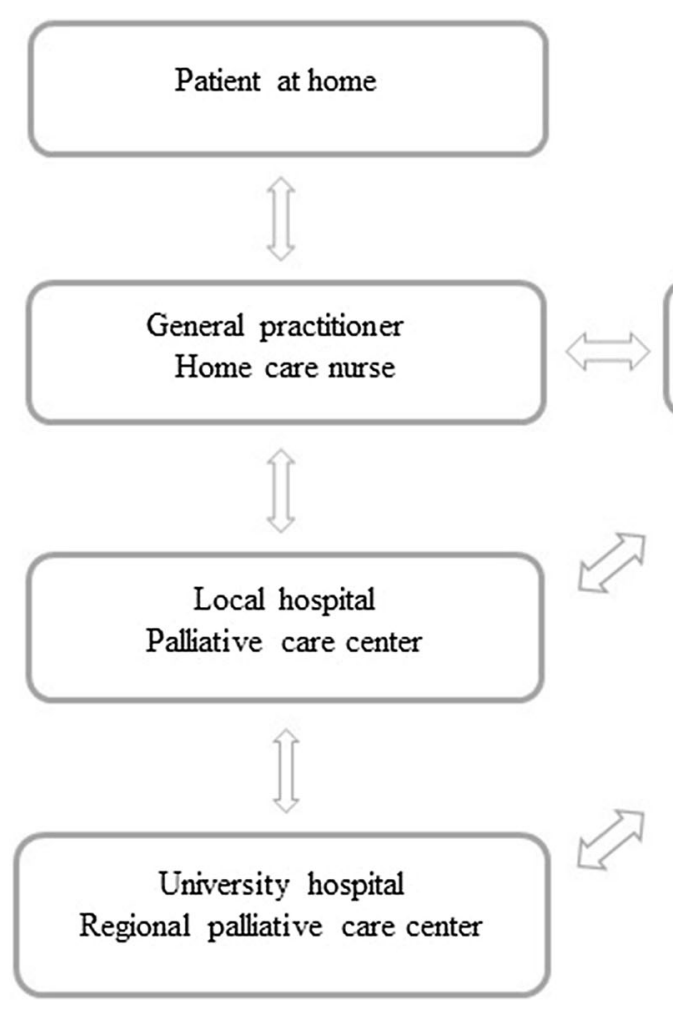

Regular nursing home

Nursing home with palliative care beds

Fig. 2 The Norwegian palliative care model

was that Norway should be a leading example of good patient care through improved coordination of services using national guidelines and SCP $[33,34]$. The Coordination Reform being implemented from 2012 urged the municipalities to take greater responsibilities for providing "advanced health care" and thereby achieving improved cost-effectiveness through adequate treatment at the right place at the right time [35].

\section{Cancer Palliative Care in the Orkdal Region of Mid-Norway}

Orkdal Hospital is the local hospital of the Orkdal region, which is a rural region $40 \mathrm{~km}$ south-west of Trondheim consisting of 19 municipalities (reorganized into 14 municipalities from Jan 01, 2020) and 97000 inhabitants [36]. The Cancer Registry of Norway reported in 2015616 new cancer cases and 4892 cancer patients living in the Orkdal region [37]. Orkdal Hospital is an integrated part of Trondheim University Hospital. The Cancer Clinic at Trondheim University Hospital has a long tradition of integrating palliative care into cancer care. The first professorship in palliative medicine in the Nordic countries was established in Trondheim in 1993 funded by the Norwegian Cancer Society [38]. In 1994 the Cancer Clinic established the Palliative Medicine Unit as one of the first specialized palliative care units internationally [20]. It was staffed with oncologists trained in palliative care through mandatory palliative care rotations many years before the terminology integrated palliative care was used. This program was also, probably as the first one, applying a SCP evaluated in a cluster randomized trial [20, 39, 40]. In 2013, the Cancer Clinic at Trondheim University Hospital was acknowledged as an ESMO Designated Centre of Integrated Oncology \& Palliative Care [41].

Orkdal Hospital offers inpatient and outpatient services within internal medicine and surgery including gynecology and orthopedics as well as radiology, laboratory, and emergency services. Since 2006 the hospital was not staffed 


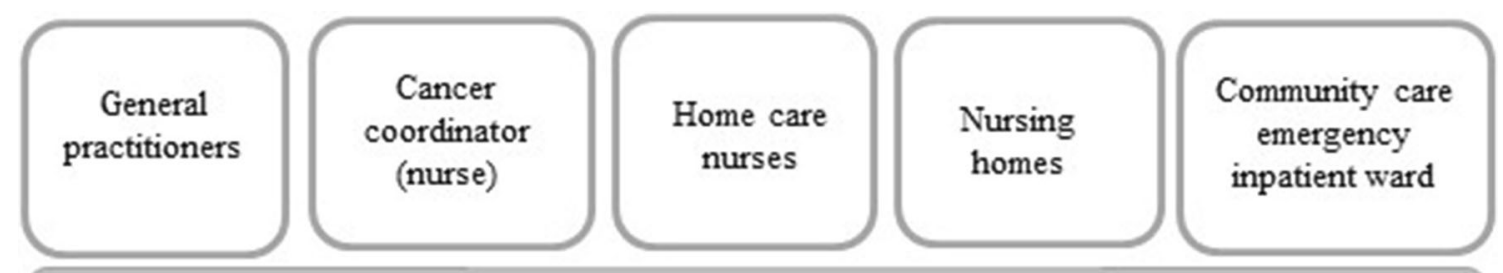

\section{Community healthcare}

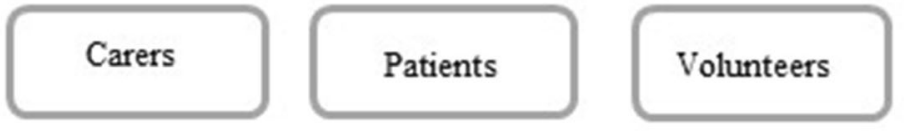

\section{Specialist healthcare}

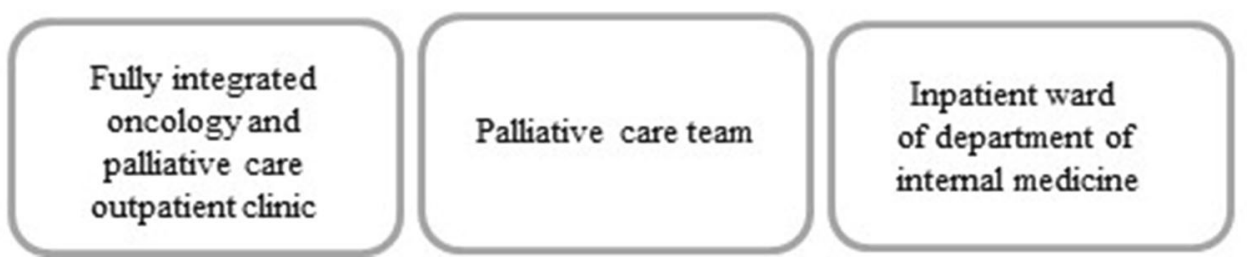

Fig. 3 Major stakeholders of Cancer and Palliative Care Services in the Orkdal region

with medical oncologist, but with cancer nurses at the inpatient wards.

In 2011, 12 of the 19 municipalities in the Orkdal Region formed a Coordination Unit with funding from the Norwegian Directorate of Health to improve health services in the region. The Coordination Unit established a 7-bed ward located at Orkdal Hospital for emergency inpatient community care with a maximum stay of three to five consecutive days. A network of resource nurses with expertise in cancer and palliative care was at the same time established in the region to enhance competence and improve collaboration between community and specialist care. Nurses from 13 municipalities and from Orkdal Hospital participated in the network. A regional cancer coordinator was employed to lead the network with funding from the Norwegian Cancer Society [42]. The network met regularly for educational purposes. Figure 3 shows the major stakeholders of cancer palliative care in the Orkdal region.

\section{Planned Development of Integrated Cancer and Palliative Care Services in the Orkdal Region}

Early 2012, a steering group was formed to lead the development of an integrated cancer and palliative care outpatient clinic at Orkdal Hospital which opened November 2012. The steering group was composed of senior management and clinical staff from the Cancer Clinic and from Orkdal Hospital, and the regional cancer coordinator. Before this, in 2010, the idea of developing a model for integrated cancer and palliative care in the Orkdal region (the Orkdal Model) was born. The model included both hospital and community health and care services. Table 1 illustrates the milestones and timeline of the development process.

\section{Patients}

Patients attending the Integrated Clinic were recruited for a descriptive study of the Clinic's patient population. Inclusion criteria were that 
Table 1 Milestones and timeline of the development process of the integrated cancer and palliative care outpatient clinic, the descriptive study, and the Orkdal Model Trial

\begin{tabular}{|c|c|c|c|c|c|c|c|c|c|c|}
\hline Milestones & 2010 & 2011 & 2012 & 2013 & 2014 & 2015 & 2016 & 2017 & 2018 & 2019 \\
\hline $\begin{array}{l}\text { Political and } \\
\text { organizational aspects }\end{array}$ & & & & & & & & & & \\
\hline $\begin{array}{l}\text { Start planning of the } \\
\text { integrated cancer and } \\
\text { palliative care model in the } \\
\text { Orkdal region }\end{array}$ & & & & & & & & & & \\
\hline $\begin{array}{l}\text { Establishment of the } \\
\text { Coordination Unit for } 12 \\
\text { municipalities }\end{array}$ & & & & & & & & & & \\
\hline $\begin{array}{l}\text { Establishment of the } \\
\text { resource network of cancer } \\
\text { nurses in } 13 \text { municipalities }\end{array}$ & & & & & & & & & & \\
\hline $\begin{array}{l}\text { Regional cancer } \\
\text { coordinator employed, } \\
\text { funded by the Norwegian } \\
\text { Cancer Society }\end{array}$ & & & & & & & & & & \\
\hline $\begin{array}{l}\text { Forming of a steering group } \\
\text { to develop the Integrated } \\
\text { Clinic }\end{array}$ & & & & & & & & & & \\
\hline $\begin{array}{l}\text { Formal agreements } \\
\text { between Trondheim } \\
\text { University Hospital and } 13 \\
\text { municipalities }\end{array}$ & & & & & & & & & & \\
\hline Clinical services & 2010 & 2011 & 2012 & 2013 & 2014 & 2015 & 2016 & 2017 & 2018 & 2019 \\
\hline $\begin{array}{l}\text { Opening of the Integrated } \\
\text { Outpatient Clinic }\end{array}$ & & & & & & & & & & \\
\hline $\begin{array}{l}\text { Establishment of the } \\
\text { extended palliative care } \\
\text { team incl. weekly meetings }\end{array}$ & & & & & & & & & & \\
\hline $\begin{array}{l}\text { Oncologist starts } \\
\text { participating in inpatient } \\
\text { ward rounds at dept. of } \\
\text { internal medicine }\end{array}$ & & & & & & & & & & \\
\hline
\end{tabular}


Table 1 continued

\begin{tabular}{|c|c|c|c|c|c|c|c|c|c|c|}
\hline $\begin{array}{l}\text { Four palliative care beds } \\
\text { established in the dept. of } \\
\text { internal medicine }\end{array}$ & & & & & & & & & & \\
\hline Intervention & 2010 & 2011 & 2012 & 2013 & 2014 & 2015 & 2016 & 2017 & 2018 & 2019 \\
\hline $\begin{array}{l}\text { Planning of the } \\
\text { interventions }\end{array}$ & & & & & & & & & & \\
\hline $\begin{array}{l}\text { Standardized care pathway } \\
\text { first made available in } 2014\end{array}$ & & & & & & & & & & \\
\hline $\begin{array}{l}\text { Educational program for } \\
\text { healthcare professionals }\end{array}$ & & & & & & & & & & \\
\hline $\begin{array}{l}\text { Information strategy for } \\
\text { patients, carers, and } \\
\text { general public }\end{array}$ & & & & & & & & & & \\
\hline Research activities & 2010 & 2011 & 2012 & 2013 & 2014 & 2015 & 2016 & 2017 & 2018 & 2019 \\
\hline $\begin{array}{l}\text { Start of the planning } \\
\text { process for the descriptive } \\
\text { study and the Orkdal Model } \\
\text { Trial }\end{array}$ & & & & & & & & & & \\
\hline $\begin{array}{l}\text { Inclusion in the descriptive } \\
\text { study of patients attending } \\
\text { the Integrated Outpatient } \\
\text { Clinic }\end{array}$ & & & & & & & & & & \\
\hline $\begin{array}{l}\text { Inclusion of patients and } \\
\text { carers in the Orkdal Model } \\
\text { Trial }\end{array}$ & & & & & & & & & & \\
\hline $\begin{array}{l}\text { Follow-up of included } \\
\text { patients and carers in the } \\
\text { Orkdal Model Trial }\end{array}$ & & & & & & & & & & \\
\hline $\begin{array}{l}\text { Inclusion and follow-up of } \\
\text { healthcare professionals in } \\
\text { the Orkdal Model Trial }\end{array}$ & & & & & & & & & & \\
\hline
\end{tabular}


the patient had cancer and attended the Integrated Clinic. There were no exclusion criteria.

\section{Measurements}

Clinical staff collected data on treatment intention, gender, date of birth, cancer diagnosis, stage of cancer, ongoing ant-cancer and pain treatments, Karnofsky Performance Status (KPS) [43], and date and place of death. Patients reported symptom intensities of in total 13 items; eight items from the ESAS-r [44]: pain, tiredness/drowsiness (assessed as one item), nausea, lack of appetite, shortness of breath, depression, anxiety, and well-being; three symptoms from the EAPC Basic Dataset [45]: insomnia, vomiting, and constipation; and in addition diarrhea and dry mouth to assess side effects of chemotherapy and opioids. All symptom intensities were measured on an 11-point numerical rating scale (NRS) from 0 (best situation) to 10 (worst situation).

\section{Statistics}

Descriptive statistical analyses were performed using IBM SPSS Statistics 25 and Stata 16.0 for Windows.

\section{Ethics}

Ethical approval for the study was obtained from the Regional Committee for Medical Research Ethics (2013/1526), and all patients gave written informed consent to participate. The study conformed to the Helsinki Declaration of 1964, as revised in 2013, concerning human and animal rights, and Springer's policy concerning informed consent has been followed.

\section{RESULTS}

\section{Structure and Organization}

The Integrated Clinic at Orkdal Hospital formed part of the Cancer Clinic at Trondheim University Hospital and was the core element in the model for integrated cancer and palliative care in the Orkdal region (the Orkdal Model). The main content of the integrated cancer and palliative care model and clinical practice is described in Table 2. The Integrated Clinic was located in the building next to the department of internal medicine as well as the community care emergency inpatient ward (Fig. 4). Such a localization was chosen in order to facilitate a real time collaboration across levels of healthcare and between healthcare professionals.

\section{Staff and Competency}

In the initial phase from November 2012, the Integrated Clinic was staffed with one oncologist, two oncology nurses and a receptionist. In the full-scale operation phase, the clinic had two full-time oncologists, three full-time oncology nurses and one full-time receptionist working 5 days/week (Mo-Fri 08 a.m.-16 p.m.). From 2019, an additional 20\% oncology nurse was employed. A palliative care team was formed at Orkdal Hospital in 2013 after a process of establishing positions for the relevant professions. The team consisted of one oncologist and oncology nurse from the Integrated Clinic; a physiotherapist, an occupational therapist (from 2017), a chaplain, a dietitian and a social worker.

It was aimed for employing oncologists with formal competence in palliative medicine at the Integrated Clinic [2]. Due to lack of oncologists with formal competence in palliative medicine in Norway, also residents in oncology trained in cancer palliative care through mandatory rotations to a specialized palliative care unit at a university hospital for at least 6 months during their oncology fellowship were employed. The nurses were all specialized cancer nurses with additional education in palliative care and previously experience from palliative cancer care. Weekly educational sessions for the palliative care team were established from the beginning. Physicians and nurses employed at the Integrated Clinic were systematically teaching colleagues at the hospital wards and in the community care emergency inpatient ward to 


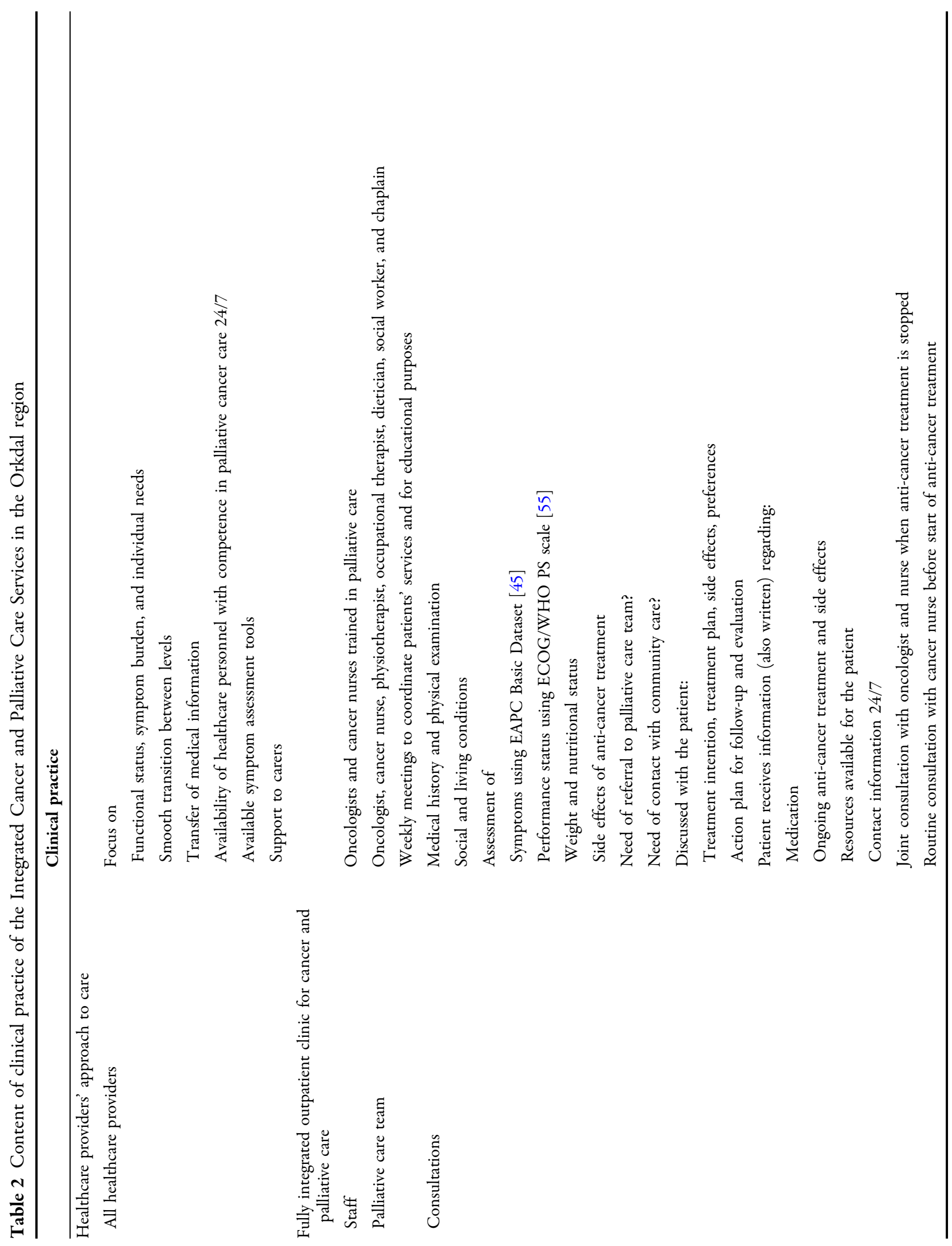




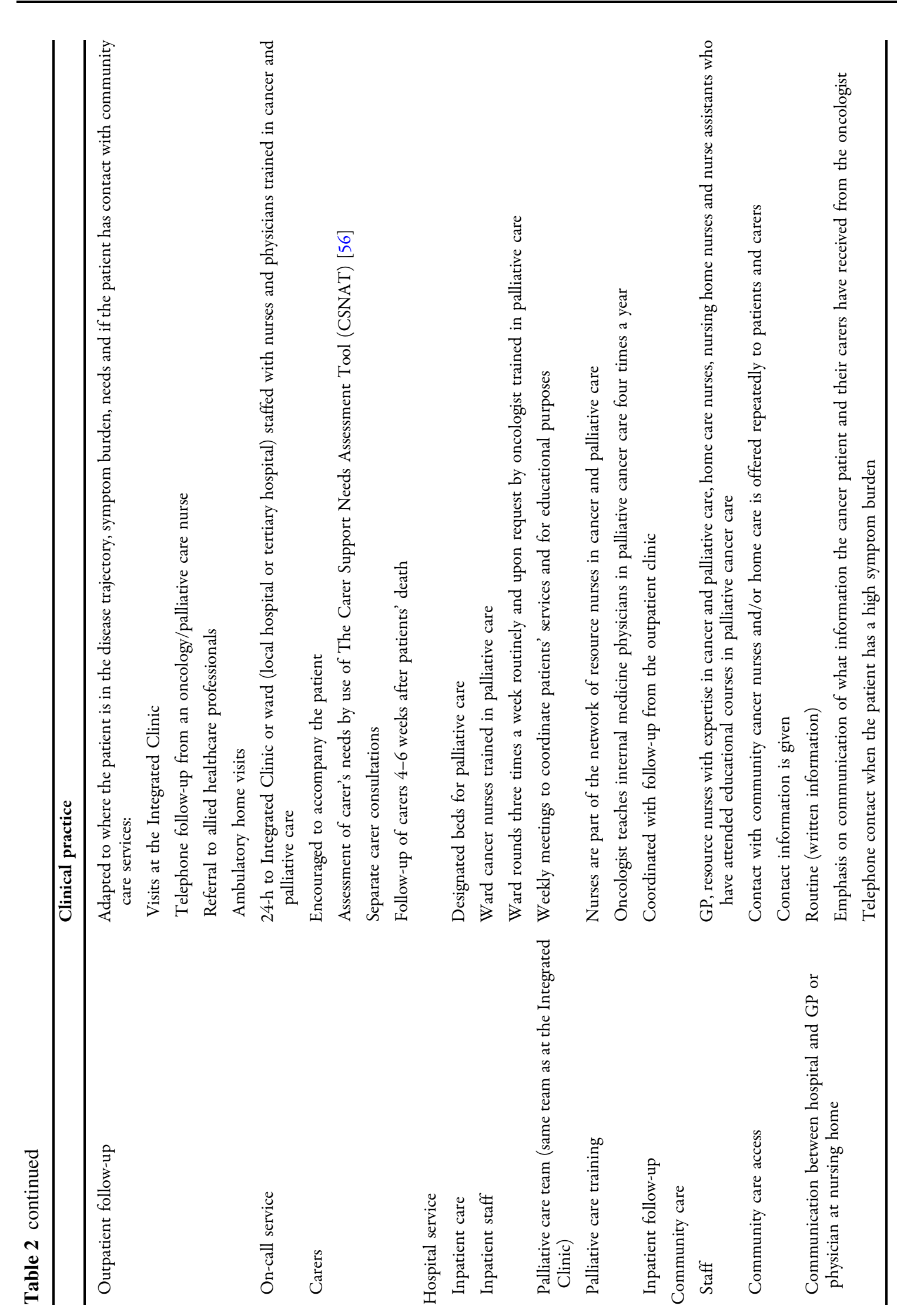




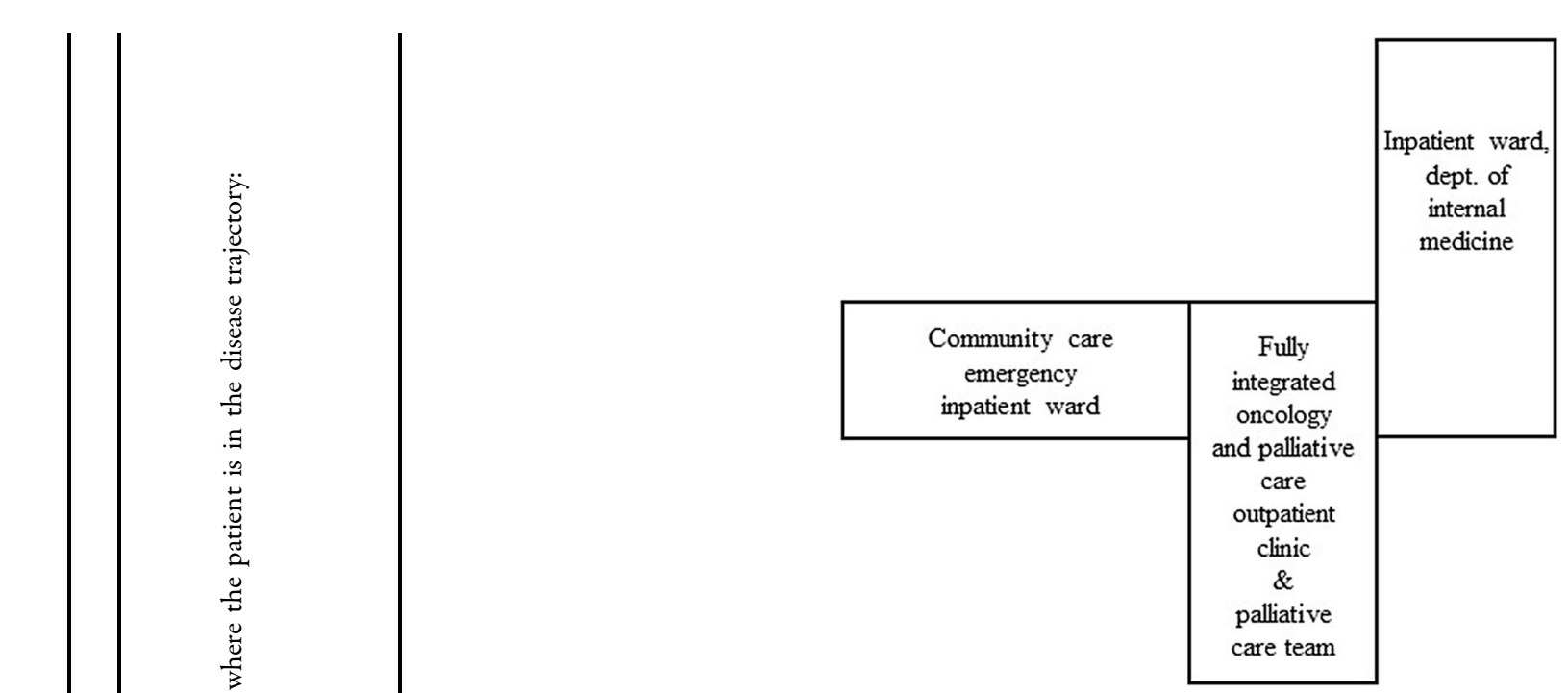

Fig. 4 Inpatient and outpatient hospital care and community care located on the same floor at Orkdal Hospital

increase knowledge and skills in cancer palliative care among other healthcare professionals.

\section{Operation}

During the initial phase, most of the patients were referred for life-prolonging treatment or palliative care. In full-scale operation phase, treatment with curative, life-prolonging and symptomatic goal was provided by one team of healthcare professionals with competence in both clinical oncology and palliative care. The palliative care team met weekly in a case management meeting to coordinate patients' services and for educational purposes. If applicable, the palliative care team discussed the patients with the resource nurses in the municipalities. The regional cancer coordinator had weekly meetings with the palliative care team to improve coordination of care. In addition to outpatient services, the Integrated Clinic collaborated with the internal medicine department at Orkdal Hospital to provide inpatient services. Cancer patients in need of inpatient hospital care other than surgery, were admitted to the internal medicine department. Four beds at the internal medicine department were dedicated to cancer palliative care from 2015 (Table 1). 
The Integrated Clinic was equipped with seven chemotherapy chairs, one bed for temporary patient observation which could also be used for chemotherapy if needed, two consultation rooms, a reception counter, a nursing station, a meeting room, a drug storage room, and a waiting and resting room for patients and their families. Chemotherapy and targeted therapy, as well as blood transfusions, pleuraland ascites drainage, and conversion to subcutaneous administration of opioids that could be completed within the opening hours, were offered. The oncologists and the oncology nurses offered regular and emergency consultations to patients. The oncology nurses also provided telephone consultations to patients at home and their families, as well as counselling services for healthcare professionals. Consultations at the inpatient wards of Orkdal Hospital, the community care emergency inpatient ward and in patients' homes were available upon request. Since 2014, an oncologist from the Integrated Clinic participated in ward rounds at the internal medicine department, in the beginning twice per week, and later increased to three times per week (Table 1). The logistics for prescription, production, and transportation of medical anti-cancer treatment was thoroughly planned; the medication was produced in Trondheim and delivered to Orkdal Hospital twice a day by car. Volunteers visited the Integrated Clinic twice a week to provide social support and serve refreshments to patients and their family.

\section{Funding of the Integrated Clinic}

The Integrated Clinic was funded by the Cancer Clinic and billing. In 2019, the user fee was 351 NOK (40 USD) per visit. At full capacity the Integrated Clinic could provide about 100 consultations per week. In 2016, 3833 outpatient consultations were registered; 1463 consultations by physicians, 979 separate consultations by nurses and 1211 chemotherapy regimens. The number of consultations by nurses increased to 1502 in 2019. The number of consultations by physicians and the number of chemotherapy regimens stayed stable between 2016 and 2019.

\section{The Referral Process}

Cancer patients were referred to the Integrated Clinic from Trondheim University Hospital, Orkdal Hospital, and GPs. Patients in need of highly specialized curative treatment (e.g. selected lymphomas and testicular cancer), and treatment not available at Orkdal Hospital, such as radiotherapy, were treated at Trondheim University Hospital in Trondheim. At evenings, nights and weekends, the emergency department at Orkdal Hospital served cancer patients in need of specialist care. Patients could be admitted to department of internal medicine or surgery/orthopedics. The referral of patients to allied healthcare professionals was need-based.

\section{The Consultations}

Systematic patient reported assessment of symptom intensities using pen and paper was applied prior to each consultation. At their first visit, usually lasting between 30 and $60 \mathrm{~min}$, the physician undertook a thorough history and a physical examination. During the consultation, symptom burden was addressed, and performance status, weight and nutritional status were assessed. Side effects for those receiving anti-cancer treatment were also addressed. Treatment intention, treatment plan, and common and serious side effects from treatment as well as the patient's preferences were discussed. Patients received information regarding medications, ongoing anti-cancer treatment, resources available for the patient and their family including contact information. Patients with complex needs and in need of community care services were offered a patient held record including contact information of relevant healthcare providers and agreements of responsibilities. Patients were encouraged to bring a family member to the consultation, and consultations with family members were arranged either separately or together with the patient as a routine. 
Patients also had a consultation with an oncology nurse before starting anti-cancer treatment as part of the Shared Decision Making (SDM) process. During this consultation the nurse ensured that patients were involved in the decisions of treatment and care planning and that they were well informed. For patients with advanced cancer not receiving anti-cancer treatment, the follow-up was dependent on symptoms, needs, geography, and to what extent community care was involved. They were offered a follow-up based on individual needs and preferences, with a combination of contact with GP and community nurses, visits at the Integrated Clinic, telephone follow-up by cancer/palliative care nurses and referral to allied healthcare professionals. If needed, they received home nursing care.

\section{Coordination of Care}

The staff at the Integrated Clinic had the coordinating role. The oncologist was in charge. To ensure access to high quality care, healthcare professionals with additional competence in cancer and palliative care were available 24/7.

\section{Communication Between and Within Hospital and Community Care}

A copy of the medical record was sent routinely from the Integrated Clinic to the patient's GP and, if applicable, to the patient's community nurse, home care nurses and/or nursing home. There were separate electronic patient record systems for specialist and community care, respectively.

\section{Characteristics of Patients Attending the Integrated Clinic}

A descriptive pilot study was carried out between October 2013 and July 2014 to get an overview of the patient population attending the Integrated Clinic (Table 1). Patient characteristics are presented in Table 3. Eighty-eight patients were recruited, representing $40 \%$ of the patients visiting the Integrated Clinic during the recruitment period. Forty-five $(51.1 \%)$ were
Table 3 Characteristics of cancer patients attending the integrated clinic $(N=88)$

\begin{tabular}{|c|c|}
\hline & $N(\%)$ \\
\hline \multicolumn{2}{|l|}{ Gender } \\
\hline Male & $43(48.9 \%)$ \\
\hline Female & $45(51.1 \%)$ \\
\hline \multicolumn{2}{|l|}{ Treatment intention } \\
\hline Curative & $36(40.9 \%)$ \\
\hline Non-curative & $52(59.1 \%)$ \\
\hline Age (mean, standard deviation) & $65.6(12.0)$ \\
\hline $\begin{array}{l}\text { Median months }(\mathrm{Q} 1-\mathrm{Q} 3)^{\mathrm{a}} \text { from cancer } \\
\text { diagnosis to first visit }\end{array}$ & $7.2(1.5-66.0)$ \\
\hline \multicolumn{2}{|l|}{ Cancer diagnosis } \\
\hline Digestive organs & $20(22.7 \%)$ \\
\hline Male genital organs & $18(20.5 \%)$ \\
\hline Breast & $22(25.0 \%)$ \\
\hline $\begin{array}{l}\text { Lymphoid, haematopoietic and related } \\
\text { tissue }\end{array}$ & $9(10.2 \%)$ \\
\hline Female genital organs & $8(9.1 \%)$ \\
\hline Other $^{\mathrm{b}}$ & $11(12.5 \%)$ \\
\hline \multicolumn{2}{|l|}{ Disease stage } \\
\hline Metastatic & $46(52.3 \%)$ \\
\hline Locally advanced & $20(22.7 \%)$ \\
\hline Localised & $22(25.0 \%)$ \\
\hline \multicolumn{2}{|l|}{ Karnofsky performance status ${ }^{c}$} \\
\hline $90-100 \%$ & $48(54.5 \%)$ \\
\hline $70-80 \%$ & $34(38.6 \%)$ \\
\hline $50-60 \%$ & $5(5.7 \%)$ \\
\hline Worse than $50 \%$ & 0 \\
\hline Missing & 1 \\
\hline \multicolumn{2}{|l|}{$\begin{array}{l}\text { Ongoing anti-cancer treatment at } \\
\text { inclusion }\end{array}$} \\
\hline Yes & $69(78.4 \%)$ \\
\hline No & $19(21.6 \%)$ \\
\hline \multicolumn{2}{|l|}{ Type of ongoing anti-cancer treatment } \\
\hline $\begin{array}{l}\text { Chemotherapy (including targeted } \\
\text { therapy) }\end{array}$ & $43(48.9 \%)$ \\
\hline
\end{tabular}


Table 3 continued

\begin{tabular}{|c|c|}
\hline & $N(\%)$ \\
\hline Radiotherapy & $1(1.1 \%)$ \\
\hline Hormone therapy & $24(27.3 \%)$ \\
\hline Other & $12(13.6 \%)$ \\
\hline \multicolumn{2}{|l|}{ Ongoing pain treatment at inclusion } \\
\hline Yes & $23(26.1 \%)$ \\
\hline No & $65(73.9 \%)$ \\
\hline \multicolumn{2}{|l|}{ Type of ongoing pain treatment } \\
\hline Paracetamol/NSAID ${ }^{\mathrm{d}}$ & $11(12.5 \%)$ \\
\hline Weak opioids (e.g. codein) & $2(2.3 \%)$ \\
\hline Strong opioids (e.g. morphine) & $10(11.4 \%)$ \\
\hline Other & $1(1.1 \%)$ \\
\hline $\begin{array}{l}\text { Median months (Q1-Q3) of study follow- } \\
\text { up }^{\mathrm{e}}\end{array}$ & $41.5(19.4-50.0)$ \\
\hline \multicolumn{2}{|l|}{ Survival status by Oct 31, 2017} \\
\hline Alive & $39(44.3 \%)$ \\
\hline Dead & $48(54.5 \%)$ \\
\hline Lost to follow-up & $1(1.1 \%)$ \\
\hline $\begin{array}{l}\text { Medical anti-cancer treatment }{ }^{\mathrm{f}} \text { last } 90 \text { days } \\
\text { of life }\end{array}$ & $22(45.8 \%)$ \\
\hline $\begin{array}{l}\text { Medical anti-cancer treatment }{ }^{\mathrm{f}} \text { last } 30 \text { days } \\
\text { of life }\end{array}$ & $6(12.5 \%)$ \\
\hline \multicolumn{2}{|l|}{ Place of death } \\
\hline Hospital & $21(43.7 \%)$ \\
\hline Nursing home & $15(31.3 \%)$ \\
\hline Home & $12(25.0 \%)$ \\
\hline
\end{tabular}

a (Q1-Q3), interquartile range

b Other cancer diagnoses included respiratory and intrathoracic organs, urinary tract, central nervous system, ill-defined, secondary and unspecified sites, and thyroid and other endocrine glands

c Karnofsky performance status was rated from 0 (dead) to 100 (no functional impairment)

d NSAID, nonsteroidal anti-inflammatory drugs

e From first visit at the Integrated Clinic to Oct 31, 2017 or death

${ }^{\mathrm{f}}$ Does not include hormone therapy
Table 4 Symptom intensities reported by patients attending the Integrated Clinic $(N=88)$

\begin{tabular}{|c|c|c|}
\hline Symptom ${ }^{a}$ & $\begin{array}{l}\text { Median } \\
(\mathbf{Q} 1-Q 3)^{b}\end{array}$ & $\begin{array}{l}\text { Rating } \geq 4^{\mathrm{c}} \\
n(\%)\end{array}$ \\
\hline Pain & $0(0-3)$ & $19(21.6)$ \\
\hline Tiredness/drowsiness & $3(0-4)$ & $30(34.1)$ \\
\hline Insomnia & $0.5(0-3)$ & $19(21.6)$ \\
\hline Nausea & $0(0-1)$ & $8(9.1)$ \\
\hline Vomiting & $0(0-0)$ & $1(1.1)$ \\
\hline Constipation & $0(0-0)$ & $6(6.8)$ \\
\hline Diarrhea & $0(0-0)$ & $4(4.5)$ \\
\hline Dry mouth & $1(0-3)$ & $20(22.7)$ \\
\hline Lack of appetite & $0(0-2)$ & $15(17.0)$ \\
\hline Shortness of breath & $0(0-3)$ & $19(12.6)$ \\
\hline Depression & $0(0-1)$ & $12(13.6)$ \\
\hline Anxiety & $0(0-1)$ & $10(11.4)$ \\
\hline Well-being & $2(0-4)$ & $26(29.5)$ \\
\hline $\begin{array}{l}\text { At least one symptom score } \\
\quad N R S \geq 4^{c}\end{array}$ & & $54(61.4)$ \\
\hline $\begin{array}{l}\text { aymptom intensity was rat } \\
\text { to } 10 \text { (the worst situation) } \\
\text { b (Q1-Q3), interquartile rar } \\
\text { ( Symptom intensity score } \\
\geq 4 \text { was defined as clinically } \\
\text { ( }\end{array}$ & $\begin{array}{l}\mathrm{d} \text { from } 0(\mathrm{t} \\
\text { americal ra } \\
\text { ignificant }\end{array}$ & scale (NRS) \\
\hline
\end{tabular}

female, mean age was 65.6 years. The most common cancer diagnoses were cancer in the digestive organs $(22.7 \%)$, male genital organs $(20.5 \%)$ or breast $(25.0 \%)$. Forty-six $(52.3 \%), 20$ $(22.7 \%)$, and $22(25.0 \%)$ had metastatic, locally advanced, and localized cancer, respectively. Fifty-two (59.1\%) were treated with non-curative intention. Eighty-two (93.1\%) had KPS $\geq 80 \%$. Sixty-nine $(78.4 \%)$ received anti-cancer treatment. Excluding hormone therapy, fiftyfour $(61.4 \%)$ received medical anti-cancer treatment (data not shown). Twenty-three (26.1\%) received pain treatment.

Patient reported symptom intensities are presented in Table 4. Fifty-four patients (61.4\%) had at least one clinically significant symptom 
score defined as NRS $\geq 4$ [46]. Tiredness/ drowsiness (34.1\%) and reduced well-being (29.5\%) were the two most prevalent clinically significant symptoms, followed by dry mouth $(22.7 \%)$, pain $(21.6 \%)$ and insomnia $(21.6 \%)$.

The patients were followed until Oct 31, 2017. Median months from first visit at the Integrated Clinic to end of study follow-up or death was 41.5 (Q1-Q3, interquartile range, 19.4-50.0). Forty-eight patients (55.5\%) died during study follow-up (Table 3 ). Twenty-two $(45.8 \%)$ and $6(12.5 \%)$ received medical anticancer treatment excluding hormone therapy during the last 90 and last 30 days of life, respectively (Table 3$)$. Twelve patients $(25.0 \%)$ died at home, 15 (31.3\%) died in nursing home, and $21(43.7 \%)$ died in hospital.

\section{The Integrated Clinic as a Venue for Research}

The Integrated Clinic was venue of a research project entitled "The Orkdal Model: development, implementation, and evaluation of collaboration between specialist and community care within palliative cancer care" (ClinicalTrials.gov Identifier: NCT02170168). This was an implementation and a quality improvement project where the clinical aim was to improve cancer and palliative care services at hospital and at community care level in the Orkdal region by integrating cancer and palliative care through the whole disease trajectory and make the trajectories as seamless as possible. The Integrated Clinic was the hub of the model. A complex intervention was developed, consisting of a SCP that guided the provision and coordination of care, an educational program for healthcare providers, and an information strategy for patients, family, healthcare providers and the general public. The overall structure of the SCP is presented in Fig. 1. The content of the SCP corresponded with clinical practice described in Table 2. Based upon referral criteria and systematic assessment, the SCP defined actions to be taken at different transition points and contained treatment recommendations. The SCP was electronically available [47]. Details of the SCP will be presented in a separate publication. Planning of the interventions started in January 2013 and implementation of the interventions started in January 2014 (Table 1). Participants were recruited from November 2014 until December 2017 and follow-up ended in December 2019 (Table 1).

\section{DISCUSSION}

This paper described the development and operation of an innovative fully integrated cancer and palliative care outpatient clinic at a local hospital in a rural region of Mid-Norway. The outpatient clinic facilitated that patients had access to the competence needed in the hospital (in- and outpatient care) and in the community care according to a systematic assessment of their needs and shared decision making. In other words, this organization model gave the patients and their families continuous real time-access to high quality cancer and palliative care where the patients were living at the given point in time. The patients and their families got access to cancer care, palliative care and community health and care services, both as a routine, and as needed. Cancer and palliative care were provided continuously by one team of healthcare professionals with competence in both oncology and palliative care. The team was physician-led and cooperated closely with community healthcare services. The team also cooperated with the tertiary university hospital in Trondheim when the patients needed more advanced oncology and/or palliative care. The oncologist and oncology nurses at the Integrated Clinic coordinated the care. A seamless integration of cancer and palliative care throughout the disease trajectory was supported. To our knowledge, this is a unique organization of a fully integrated cancer clinic [48].

The outpatient clinic setting has been recognized as the optimal place to offer early access to palliative care [49]. The distinctive advantage of providing palliative care integrated with cancer care in cancer outpatient clinics is that patients can be followed up longitudinally. Establishment of a relationship between the 
patient and the palliative care team early in the disease trajectory enhances shared decision making, care planning, access to community care resources, and early detection and management of symptoms before they become severe [11].

Stand-alone palliative care clinics and cancer clinics embedding a palliative care consultant or palliative care team, are two common models of outpatient palliative care services $[48,50]$. Temel et al. presented in 2010 an outpatient cancer palliative care model where patients with newly diagnosed metastatic lung cancer in addition to regular cancer care were offered regular meetings with palliative care physicians and nurses [7]. The focus during the meetings was on physical and psychosocial symptoms and needs, establishing goals of care, and offering care and treatment services according to their individual needs and desires [7]. The Zimmermann model from 2014 used a similar approach [8]. In addition, home care nursing services and transfer to a home palliative care physician when requested or when patient's ECOG performance status was 3 or worse was offered [8]. In the ENABLE II project Bakitas et al. educated patients with advanced cancer about key palliative care principles and crisis prevention through practice in decision-making skills, symptom management, communication, and advance care planning. The intervention was primarily conducted by telephone by a palliative care nurse specialist concurrent with anti-cancer treatment, and was shown to have an effect on quality of life and mood $[6,51]$. In a Belgian nurse-led model, the intervention consisted of training of palliative care nurses and a physician in cancer treatments as well as monthly palliative care consultations by palliative care nurses focusing on illness understanding and perception, symptom burden, psychological and spiritual coping, medical decision making, and monthly symptom assessments [10]. The palliative care physician had a consultation with the patients after referral from the palliative care nurses. In addition, the palliative care nurses participated weekly in multidisciplinary oncology meetings [10]. Our model is conceptually different from these models evaluated in RCTs, where palliative care is an add-on service with a strong psychosocial angling, coordination of the existing cancer care, and involvement and teaching of the patients. Less, if any, direct involvement of the oncology team seems to be a part of these constructs [2].

Our model introduces a new model of early access to palliative care throughout the whole disease trajectory for cancer patients. The model can be understood as a fully integrated timebased model as described in the recent Lancet Oncology Commission paper [2]. This may be particularly cost-effective for an outpatient clinic in a local hospital with a limited patient volume. But also, a model for larger hospitals in order to reach the goal of full integration at institutional level while the working flow for each individual patient needs to be custommade and the degree of integration should be flexible. The present model is based on the same concepts, but further refined and adapted to a local hospital, as the model evaluated and presented in a cluster RCT from 2000 [20].

Integration can either be parallel (work in parallel or series), coordinated (partially; separate structures are operated within a system), or full integration (resources are pooled) [2]. When it comes to integration of oncology and palliative care, the best model has not yet been established $[2,48]$. Our model was developed to fit a local hospital in a rural area and its surrounding municipalities. The size of the hospital and the resources available did not permit to create a structure consisting of one oncology structure and one palliative care structure. We believe that our model is a sustainable model for smaller hospitals in rural regions contributing to give cancer patients better cancer and palliative care closer to home.

Most Norwegian cancer patients (around 65\%) die in their communities, either at home $(10-15 \%)$ or in nursing homes (around 50\%) [52]. A population-based study from England, UK, showed that patients living in rural areas had worse geographic access to hospitals than patients living in urban areas and were more likely to die at home [53]. Norway is a sparsely populated country, and many Norwegians have long travel distances to hospitals and to palliative care units. This underlines the importance 
of bringing competence in cancer and palliative care out in the communities. This is illustrated by the fact that the travel time by car for cancer patients from home to the hospital was reduced with $45 \mathrm{~min}$. after the implementation of this model. In our pilot study, $25 \%$ died at home.

Challenges to the presented model may be several. The Integrated Clinic was planned to be staffed with oncologists with formal competence in palliative medicine. Due to shortage of staff with this competence, this was however not possible. We still believe that the model in the future must consist of dual specialists in palliative medicine and oncology. In Norway, palliative medicine is a formal competence field for physicians [54]. Not having a dedicated oncologist with additional formal competence in palliative medicine providing palliative care may over time reduce the palliative care content of the consultations and make the model vulnerable. However, at the Cancer Clinic at Trondheim University Hospital there was a long tradition of integrating palliative care into cancer care and in 'uniting' the palliative care culture and the oncology culture [2, 20]. In MidNorway, all oncologists had mandatory rotations to the Palliative Medicine Unit during their fellowship, and there was a close collaboration between the Integrated Clinic at Orkdal Hospital and the Palliative Medicine Unit at Trondheim University Hospital where oncologists with additional formal competence in palliative medicine worked. In addition, the SCP for palliative cancer patients developed as part of the Orkdal Model project, facilitated the delivery of integrated oncology and palliative care.

Implementation and changes within healthcare are challenging and barriers have been identified related to e.g. education, competencies, policy, and culture $[2,54]$. Resistance at several levels was to be expected. However, in this region, cancer- and palliative care services were asked for, and the establishment was widely supported by the involved organisations, healthcare personnel and patients and families. The establishment took advantage of already existing structures. Furthermore, teaching of involved healthcare professionals in oncology and palliative care reduced barriers related to e.g. collaboration. One important barrier was to motivate oncologists at the university hospital to refer patients to colleagues at the local hospital, and to follow-up in community care. Both attitudes among colleagues and the reimbursement system contributed to this.

In the descriptive pilot study carried out at the Integrated Clinic, the majority of the patients $(59.1 \%)$ included were treated with non-curative intention, indicating a significant role of the Integrated Clinic in providing palliative care during cancer treatment. The patients had low symptom burden (median symptom scores 0-3) and high performance status $(93.1 \%$ had KPS $\geq 80 \%$ ), making it possible to offer palliative care services at an early stage before symptoms become severe. Sixtyone percent had at least one clinically significant symptom (NRS $\geq 4$ ), highlighting the importance of systematic and regular symptom assessments among all cancer patients regardless of performance status and treatment intention [46].

Only $40 \%$ of the patients visiting the Integrated Clinic were enrolled in the descriptive study. This was due to lack of experience with research at the Integrated Clinic. When the pilot study started, the Integrated Clinic was recently opened, and focus was on establishing clinical practice. The healthcare personnel working at the Integrated Clinic had to gain experience in research. This population may not be representative for the whole population attending the Integrated Clinic. However, the population illustrates a need for palliative care concurrent with cancer care (a high proportion of the patients had metastatic disease and were treated with non-curative intention), confirming that the 'right patients' were referred to the Integrated Clinic.

\section{CONCLUSION}

This paper describes the development and operation of an innovative, fully early integrated one-stop oncology and palliative care outpatient clinic at a local hospital in a rural region of Mid-Norway. In this fully Integrated Clinic, cancer and palliative care were provided 
by one team of healthcare providers. The fully Integrated Clinic communicated and collaborated closely with its local hospital, its affiliated tertiary hospital and community health and care services to provide timely referral, enhanced continuity, and improved coordination and quality of care. This model of care is particularly relevant to the early integration of cancer and palliative care in a smaller hospital and the provision of cancer and palliative care in a rural district.

\section{ACKNOWLEDGEMENTS}

The authors thank all the patients who joined the descriptive study reported in this article and the healthcare professionals who helped in patient recruitment and data collection.

Funding. This project was funded by the Norwegian Extra Foundation for Health and Rehabilitation, the Norwegian Cancer Society, the Norwegian Directorate of Health [11/234126], the Cancer Foundation at Trondheim University Hospital, the Floriani FoundationMilan [del.CDA 22/11/12], and Norwegian Women's Public Health Association Orkdal. Norwegian University of Science and Technology funded the rapid service fee.

Authorship. All named authors meet the International Committee of Medical Journal Editors (ICMJE) criteria for authorship for this article, take responsibility for the integrity of the work as a whole, and have given their approval for this version to be published.

Authorship Contributions. Anne-Tove Brenne and Anne Kari Knudsen contributed equally.

Prior Presentation. The content of this manuscript was presented as poster at the 14th World Congress of the EAPC in Copenhagen, Denmark, 8-10 May 2015.
Disclosures. Anne-Tove Brenne, Anne Kari Knudsen, Sunil Xavier Raj, Laila Skjelvan, JoÅsmund Lund, Morten Thronæs, Erik Torbjørn Løhre, Liv Ågot Hågensen, Cinzia Brunelli, and Stein Kaasa have nothing to disclose. At the time of the study Cinzia Brunelli was also affiliated with Norwegian University of Science and Technology, Trondheim, Norway; Cancer Clinic, St. Olavs Hospital, Trondheim University Hospital, Trondheim, Norway.

Compliance with Ethics Guidelines. Ethical approval for the study was obtained from the Regional Committee for Medical Research Ethics $(2013 / 1526)$, and all patients gave written informed consent to participate. The study conformed to the Helsinki Declaration of 1964, as revised in 2013, concerning human and animal rights, and Springer's policy concerning informed consent has been followed.

Data Availability. The datasets generated and/or analyzed during the current study are available from the corresponding author on reasonable request.

Open Access. This article is licensed under a Creative Commons Attribution-NonCommercial 4.0 International License, which permits any non-commercial use, sharing, adaptation, distribution and reproduction in any medium or format, as long as you give appropriate credit to the original author(s) and the source, provide a link to the Creative Commons licence, and indicate if changes were made. The images or other third party material in this article are included in the article's Creative Commons licence, unless indicated otherwise in a credit line to the material. If material is not included in the article's Creative Commons licence and your intended use is not permitted by statutory regulation or exceeds the permitted use, you will need to obtain permission directly from the copyright holder. To view a copy of this licence, visit http://creativecommons.org/licenses/by$\mathrm{nc} / 4.0 /$. 


\section{REFERENCES}

1. World Health Organization. WHO Definition of Palliative Care: WHO. http://www.who.int/cancer/ palliative/definition/en/. Accessed 4 Apr 2019.

2. Kaasa S, Loge $\mathrm{JH}$, Aapro $\mathrm{M}$, et al. Integration of oncology and palliative care: a Lancet Oncology Commission. Lancet Oncol. 2018;19(11):e588-653.

3. World Health Organization. WHA58.22 Resolution on Cancer Control: World Health Organization; $2005 . \quad$ http://www.who.int/cancer/eb1143/en/. Accessed 20 Sept 2019.

4. Murray SA, Kendall M, Boyd K, Sheikh A. Illness trajectories and palliative care. $\mathrm{Br}$ Med $\mathrm{J}$. 2005;330(7498):1007-11.

5. Hui D, Elsayem A, De la Cruz M, et al. Availability and integration of palliative care at US cancer centers. JAMA. 2010;303(11):1054-61.

6. Bakitas M, Lyons KD, Hegel MT, et al. Effects of a palliative care intervention on clinical outcomes in patients with advanced cancer: the Project ENABLE II randomized controlled trial. JAMA. 2009;302(7): 741-9.

7. Temel JS, Greer JA, Muzikansky A, et al. Early palliative care for patients with metastatic non-smallcell lung cancer. N Engl J Med. 2010;363(8):733-42.

8. Zimmermann C, Swami N, Krzyzanowska M, et al. Early palliative care for patients with advanced cancer: a cluster-randomised controlled trial. Lancet. 2014;383(9930):1721-30.

9. Hannon B, Swami N, Rodin G, Pope A, Zimmermann C. Experiences of patients and caregivers with early palliative care: a qualitative study. Palliat Med. 2017;31(1):72-81.

10. Vanbutsele G, Pardon K, Van Belle S, et al. Effect of early and systematic integration of palliative care in patients with advanced cancer: a randomised controlled trial. Lancet Oncol. 2018;19(3):394-404.

11. Hui D, Kim SH, Roquemore J, Dev R, Chisholm G, Bruera E. Impact of timing and setting of palliative care referral on quality of end-of-life care in cancer patients. Cancer. 2014;120(11):1743-9.

12. Gotfrit J, Jonker C, Zhang T, et al. Inpatients versus outpatients with advanced non-small cell lung cancer: characteristics and outcomes. Cancer Treat Res Commun. 2019;19:100130.

13. Hannon B, Swami N, Pope A, et al. The oncology palliative care clinic at the Princess Margaret Cancer Centre: an early intervention model for patients with advanced cancer. Support Care Cancer. 2015;23(4):1073-80.

14. Rocque GB, Mullvain JA, Eickhoff J, Cleary JF, Campbell TC. Integrating palliative care into the oncology clinic: a joint management approach. Palliat Med. 2016;30(5):510-2.

15. Blackhall LJ, Read P, Stukenborg G, et al. CARE track for advanced cancer: impact and timing of an outpatient palliative care clinic. J Palliat Med. 2016;19(1):57-63.

16. Strasser F, Sweeney C, Willey J, Benisch-Tolley S, Palmer JL, Bruera E. Impact of a half-day multidisciplinary symptom control and palliative care outpatient clinic in a comprehensive cancer center on recommendations, symptom intensity, and patient satisfaction: a retrospective descriptive study. J Pain Symptom Manag. 2004;27(6):481-91.

17. Smith AK, Thai JN, Bakitas MA, et al. The diverse landscape of palliative care clinics. J Palliat Med. 2013;16(6):661-8.

18. Rabow MW, Smith AK, Braun JL, Weissman DE. Outpatient palliative care practices. Arch Intern Med. 2010;170(7):654-5.

19. Stjernsward J. Palliative care: the public health strategy. J Public Health Policy. 2007;28(1):42-55.

20. Jordhoy MS, Fayers P, Saltnes T, Ahlner-Elmqvist M, Jannert M, Kaasa S. A palliative-care intervention and death at home: a cluster randomised trial. Lancet. 2000;356(9233):888-93.

21. Morita T, Miyashita M, Yamagishi A, et al. Effects of a programme of interventions on regional comprehensive palliative care for patients with cancer: a mixed-methods study. Lancet Oncol. 2013;14(7): 638-46.

22. Holmenlund K, Sjogren P, Nordly M. Specialized palliative care in advanced cancer: what is the efficacy? A systematic review. Palliat Support Care. 2017;15(6):724-40.

23. Hui D, Bruera E. Models of integration of oncology and palliative care. Ann Palliat Med. 2015;4(3): 89-98.

24. European Pathway Association. Care Pathways. http://e-p-a.org/care-pathways/. Accessed 29 Feb 2020.

25. Rotter T, Kinsman L, James E, Machotta A, Steyerberg EW. The quality of the evidence base for clinical pathway effectiveness: room for improvement in the design of evaluation trials. BMC Med Res Methodol. 2012;12:80. 
26. Collins A, Sundararajan V, Burchell J, et al. Transition points for the routine integration of palliative care in patients with advanced cancer. J Pain Symptom Manag. 2018;56(2):185-94.

27. Ringard Å, Sagan A, Sperre Saunes I, Lindahl A. Norway: health system review. Health Syst Transit. 2013;15(8):1-162.

28. The Norwegian Directorate of Health. Fastlegestatistikk (In Norwegian) 2019 [updated 30.04.19. https://www.helsedirektoratet.no/statistikk/statistikk/ fastlegestatistikk. Accessed 8 Oct 2019.

29. Kaasa S, Jordhoy MS, Haugen DF. Palliative care in Norway: a national public health model. J Pain Symptom Manag. 2007;33(5):599-604.

30. Official Norwegian Report. NOU 2017: 16 På liv og død- Palliasjon til alvorlig syke og døende (In Norwegian). Oslo: Departementenes sikkerhets- og serviceorganisasjon; 2017.

31. Helse Vest IKT. Nasjonalt register over palliative virksomheter (In Norwegian): Helse Vest; 2019. https://www.pallreg.no/. Accessed 17 Sept 2019.

32. The Norwegian Directorate of Health. Nasjonalt handlingsprogram for palliasjon i kreftomsorgen (In Norwegian) [Norwegian National Guidelines]. Oslo: The Norwegian Directorate of Health; 2019. https://www.helsedirektoratet.no/tema/palliasjon. Accessed 18 Oct 2019.

33. Norwegian Ministry of Health and Care Services. Together-against cancer National Cancer Strategy 2013-2017: Norwegian Ministry of Health and Care Services; 2013. https://www.regjeringen.no/cont entassets/07cd14ff763444a3997de1570b85fad1/i1158_together-against_cancer_web.pdf. Accessed 11 Dec 2017.

34. Norwegian Ministry of Health and Care Services. Leve med kreft- Nasjonal kreftstrategi (2018-2022) (In Norwegian): Norwegian Ministry of Health and Care Services; 2018. https://www.regjeringen.no/ contentassets/266bf1eec38940888a589ec86d79da20/ regjeringens_kreftstrategi_180418.pdf. Accessed 14 Apr 2019.

35. Norwegian Ministry of Health and Care Services. The Coordination Reform Proper Treatment-at the right place and right time: Norwegian Ministry of Health and Care Services; 2009. Report No. 47 (2008-2009) to the Storting. https://www.regjeri ngen.no/contentassets/d4f0e16ad32e4bbd8d8ab 5c21445a5dc/en-gb/pdfs/stm200820090047000en_ pdfs.pdf. Accessed 11 Dec 2017.

36. Statistics Norway. Population and population changes, Q2 2015 2015. https://www.ssb.no/en/ befolkning/statistikker/folkendrkv/kvartal/2015-
08-20? fane=tabell\&sort=nummer\&tabell $=236795$. Accessed 9 Oct 2019.

37. Cancer Registry of Norway. Cancer Registry of Norway; 2015. https://www.kreftregisteret.no/en/ The-Registries/data-and-statistics/. Accessed 4 Apr 2019.

38. Beishon M. Stein Kaasa: let me show you what integrated palliative care can do. Cancer World. 2012;46:4-11.

39. Ringdal GI, Jordhoy MS, Ringdal K, Kaasa S. The first year of grief and bereavement in close family members to individuals who have died of cancer. Palliat Med. 2001;15(2):91-105.

40. Jordhoy MS, Fayers P, Loge JH, Ahlner-Elmqvist M, Kaasa S. Quality of life in palliative cancer care: results from a cluster randomized trial. J Clin Oncol. 2001;19(18):3884-94.

41. European Society for Medical Oncology. ESMO Designated Centres of Integrated Oncology \& Palliative Care: European Society for Medical Oncology. https://www.esmo.org/Patients/DesignatedCentres-of-Integrated-Oncology-and-Palliative-Care. Accessed 13 May 2019.

42. The Norwegian Cancer Society. Kreftkoordinatorsatsingen (In Norwegian) 2019. https://kreftforeni ngen.no/vi-pavirker/kreftforeningen-mener/viktigepolitiske-saker/kreftkoordinatorsatsingen/. Accessed 17 Sept 2019.

43. Yates JW, Chalmer B, McKegney FP. Evaluation of patients with advanced cancer using the Karnofsky performance status. Cancer. 1980;45(8):2220-4.

44. Watanabe SM, Nekolaichuk C, Beaumont C, Johnson L, Myers J, Strasser F. A multicenter study comparing two numerical versions of the Edmonton Symptom Assessment System in palliative care patients. J Pain Symptom Manag. 2011;41(2): 456-68.

45. Sigurdardottir KR, Kaasa S, Rosland JH, et al. The European Association for Palliative Care basic dataset to describe a palliative care cancer population: results from an international Delphi process. Palliat Med. 2014;28(6):463-73.

46. Raj SX, Thronaes M, Brunelli C, Hjermstad MJ, Klepstad P, Kaasa S. A cross-sectional study on prevalence of pain and breakthrough pain among an unselected group of outpatients in a tertiary cancer clinic. Support Care Cancer. 2014;22(7): 1965-71.

47. St. Olavs Hospital Trondheim University Hospital. Standardisert pasientforløp: Den palliative kreftpasient i Orkdalsregionen. Trondheim 2014 
[updated Feb 23, 2018. https://data.stolav.no/ eqspublic/pasientforlop/docs/doc_25343/index. html. Accessed 7 Mar 2020.

48. Fulton JJ, LeBlanc TW, Cutson TM, et al. Integrated outpatient palliative care for patients with advanced cancer: a systematic review and metaanalysis. Palliat Med. 2019;33(2):123-34.

49. Hui D, Bruera E. Integrating palliative care into the trajectory of cancer care. Nat Rev Clin Oncol. 2016;13(3):159-71.

50. Hui D, Bansal S, Strasser F, et al. Indicators of integration of oncology and palliative care programs: an international consensus. Ann Oncol. 2015;26(9):1953-9.

51. Bakitas M, Lyons KD, Hegel MT, et al. The project ENABLE II randomized controlled trial to improve palliative care for rural patients with advanced cancer: baseline findings, methodological challenges, and solutions. Palliat Support Care. 2009; 7(1):75-86.

52. Norwegian Institute of Public Health. "De fleste dør på sykehjem, få dør hjemme" (In Norwegian):
Norwegian Institute of Public Health; 2018 [updated 2019 Jan 24]. https://www.fhi.no/nyheter/ 2018/de-fleste-dor-pa-sykehjem/. Accessed 19 Sept 2019.

53. Chukwusa E, Verne J, Polato G, Taylor R, Higginson IJ, Gao W. Urban and rural differences in geographical accessibility to inpatient palliative and end-of-life (PEoLC) facilities and place of death: a national population-based study in England, UK. Int J Health Geogr. 2019;18(1):8.

54. Aldridge MD, Hasselaar J, Garralda E, et al. Education, implementation, and policy barriers to greater integration of palliative care: a literature review. Palliat Med. 2016;30(3):224-39.

55. Oken MM, Creech RH, Tormey DC, et al. Toxicity and response criteria of the Eastern Cooperative Oncology Group. Am J Clin Oncol. 1982;5(6): 649-55.

56. Ewing G, Brundle C, Payne S, Grande G, National Association for Hospice at H. The Carer Support Needs Assessment Tool (CSNAT) for use in palliative and end-of-life care at home: a validation study. J Pain Symptom Manag. 2013;46(3):395-405. 